\title{
Development of a double monoclonal antibody-based sandwich enzyme-linked immunosorbent assay for detecting canine distemper virus
}

\author{
Yuan Zhang ${ }^{1,2} \cdot$ Gang Xu $^{1,2} \cdot$ Lu Zhang $^{1,2} \cdot$ Jiakai Zhao ${ }^{1,2} \cdot$ Pinpin $\mathrm{Ji}^{1,2} \cdot$ Yaning $\mathrm{Li}^{1,2} \cdot$ Baoyuan Liu ${ }^{1,2} \cdot$ Jingfei Zhang $^{3}$. \\ Qin Zhao ${ }^{1,2} \cdot$ Yani Sun $^{1,2} \cdot$ En-Min Zhou ${ }^{1,2}$
}

Received: 6 July 2020 / Revised: 23 October 2020 / Accepted: 31 October 2020 / Published online: 7 November 2020

(C) The Author(s) 2020

\begin{abstract}
Canine distemper virus (CDV) infection causes mass mortality in diverse carnivore species. For effective virus surveillance, rapid and sensitive assays are needed to detect CDV in field samples. In this study, after BABL/c mice were immunized with recombinant $\mathrm{CDV}$-fusion $(\mathrm{F})$ protein, monoclonal antibodies (mAbs) against recombinant CDV-F protein (designated 1A5, 1A6, and 7D5) were produced using traditional hybridoma cell technology. Next, capture antibody (1A6, $800 \mathrm{ng} / \mathrm{well}$ ) and horseradish peroxidase (HRP)-conjugated detection antibody (HRP-7D5, 1:100, $500 \mathrm{ng} /$ well) were used in a double monoclonal antibody-based sandwich enzyme-linked immunosorbent assay (ELISA) for CDV detection after optimization of both mAb amounts per well using a checkerboard titration test. Based on sandwich ELISA test results for 120 known CDV-negative samples, the cutoff value for a positive result was set to an $\mathrm{OD}_{450 \mathrm{~nm}}$ value $\geq 0.196$. As compared with test results obtained from commercial immune colloidal gold test strips, the low limits of detection for the two assays were revealed to be $100 \mathrm{TCID}_{50}$ per $100 \mu \mathrm{L}$. In addition, the sandwich ELISA agreed $100 \%$ and $96.4 \%$ with commercial immune colloidal gold test strips when testing serum and stool samples. The sandwich ELISA assay provided statistically similar CDV detection. Thus, the sandwich ELISA developed here to detect CDV in fecal and serum samples provided good sensitivity, high specificity, and good reproducibility and should serve as an ideal method for large-scale surveillance of CDV infections in carnivores.
\end{abstract}

\section{Key points}

- Three CDV mAbs that recognized different epitopes and bound to virion were generated.

- The sandwich ELISA based mAbs to detect CDV in fecal and serum samples was developed.

- The sandwich ELISA is an ideal method for detecting CDV infections in the field.

Keywords Canine distemper virus · CDV-F protein · Monoclonal antibody · Sandwich ELISA

Yuan Zhang and Gang Xu contributed equally to this work.

Yani Sun

sunyani@nwsuaf.edu.cn

$\triangle$ En-Min Zhou

zhouem@nwsuaf.edu.cn

1 Department of Preventive Veterinary Medicine, College of Veterinary Medicine, Northwest A\&F University, Yangling 712100, Shaanxi, China

2 Scientific Observing and Experimental Station of Veterinary Pharmacology and Diagnostic Technology, Ministry of Agriculture, Yangling 712100, Shaanxi, China

3 Xi'an Center for Animal Disease Control and Prevention, Xi'an 710061, Shaanxi, China

\section{Introduction}

Canine distemper virus (CDV) can infect a broad range of carnivores, including Canidae, Procyonidae, Felidae, Mustelidae, Mephitidae, Ailuridae, Viverridae, Hyaenidae, and Phocidae (Beineke et al. 2015; Loots et al. 2017). Viral infection can lead to the development of complex clinical signs that include respiratory, gastrointestinal, and neurological symptoms. Generally, the mortality rates of CDV infection for most susceptible animal species have ranged from 30 to $80 \%$, while the corresponding rate in ferrets is $100 \%$ (Deem et al. 2000; von Messling et al. 2003). Recently, the diseases caused by CDV infection have even occurred in vaccinated dogs and important economic animal species, including 
farmed mink, fox, and racoon dog, resulting in serious economic losses (von Messling et al. 2003; Pope et al. 2016). In addition, CDV infections of many endangered animals, including Amur tiger, Ethiopian wolf, and giant panda species, have also been reported (Loots et al. 2017).

$\mathrm{CDV}$, a member of the genus Morbillivirus within the family Paramyxoviridae, is an enveloped, non-segmented, singlestranded RNA virus (Duque-Valencia et al. 2019; Li et al. 2018a, b). Its 15,690-nt viral genome encodes six open reading frames (ORFs) corresponding to six proteins: nuclear protein $(\mathrm{N})$, phosphoprotein $(\mathrm{P})$, matrix protein $(\mathrm{M})$, fusion protein $(\mathrm{F})$, hemagglutinin protein $(\mathrm{H})$, and large protein $(\mathrm{L})$ (Martinez-Gutierrez and Ruiz-Saenz 2016; Sidhu et al. 1993). Of these proteins, CDV H and F glycoproteins are located on viral particle surfaces and are responsible for virus attachment to host cells and fusion with the host cell membrane (Rendon-Marin et al. 2019). Importantly, several previous studies have shown that the F protein is a highly conserved immunogenic protein and an important antigen for inducing neutralizing antibodies against CDV (David et al. 2019).

Diagnosis of CDV infection is usually based on clinical signs and history. In early stages of CDV infection in unvaccinated puppies, CDV infection is often indistinguishable from other diseases, such as kennel cough. Thus, the rapid and accurate detection is an important measure for controlling disease. Currently, many experimental detection methods have been developed to diagnose CDV infection accurately, such as virus isolation, reverse transcription polymerase chain reaction (RTPCR), real-time RT-PCR, immunohistochemical detection, and immune colloidal gold test strips (Barben et al. 1999; Cho et al. 2014; Elia et al. 2006; Martella et al. 2007; Nemeth et al. 2018; Soma et al. 2003; Wang et al. 2017). At present, detection of CDV infection has mainly relied on RT-PCR or real-time RT-PCR and testing the CDV viral particles using immune colloidal gold test strips. However, RT-PCR assays can only be carried out in well-equipped laboratories (Kim et al. 2006; Wang et al. 2018), while immune colloidal gold test strip testing is expensive and therefore unsuitable for testing of large numbers of samples. For these reasons, here we developed a sandwich enzyme-linked immunosorbent assay (ELISA) as a sensitive, specific, and easy-to-implement assay for detection of viral antigens that could be suitable for high-throughput testing applications. This sandwich ELISA was designed to detect $\mathrm{CDV}$ in serum and fecal samples based on specific binding of monoclonal antibodies (mAbs) to CDV-F protein in this work. This monoclonal antibody-based sandwich ELISA offers good reliability, specificity, simplicity, and reproducibility for clinical detection of CDV.

\section{Materials and methods}

\section{Cells and viruses}

Vero cells and SP2/0 murine myeloma cells were purchased from ATCC and were cultured in Dulbecco's Modified Eagle's Medium (DMEM, Life Technologies Corp, USA) supplemented with $10 \%$ fetal bovine serum (FBS, Gibco, USA) at $37{ }^{\circ} \mathrm{C}$ in $5 \% \mathrm{CO}_{2}$.

Canine distemper virus (CDV) strain Onderstepoort (GenBank number: EU143737.1) was propagated in Vero cells using a viral stock with $50 \%$ tissue culture infective dose $\left(\mathrm{TCID}_{50}\right)$ value of $10^{5} / \mathrm{mL}$.

\section{Expression and purification of recombinant CDV-F protein}

The complete gene encoding the CDV-F protein was cloned based on the CDV reference genome sequence (GenBank accession number KP677502) and ligated to pET-28a vector (Novagen USA) by GENEWIZ Company. Next, the positive recombinant plasmid was transformed into Escherichia coli (E. coli) BL21 (DE3)-competent cells for the expression of CDV-F protein followed by screening of transformants for the desired plasmid construct. Next, the expression of recombinant CDV-F protein in verified transformants was induced by addition of $0.1 \mathrm{mM}$ isopropyl- $\beta$-D-thiogalactoside (IPTG); then, bacteria were harvested by centrifugation, lysed by sonication. After centrifugation of the sonicate, the pellet containing inclusion bodies was washed then resuspended in a solution containing $8 \mathrm{M}$ urea in phosphate-buffered saline (PBS, $\mathrm{pH}$ 7.2). Finally, the recombinant CDV-F protein was purified via metal affinity chromatography (IMAC) using a Ni-NTA Superflow chelating agarose column according to the manufacturer's instructions. Expression, purification, and antigenicity of the CDV-F protein were analyzed using SDSPAGE and Western blot assays. For the Western blot assay, the commercially available dog anti-CDV antibodies (XiNuo Bio-Technology Limited, Changchun, China) were served as the primary antibody.

\section{Production and characterization of mAbs against CDV-F protein}

Four 6-week-old BALB/c mice were purchased from the Experimental Animal Center of Xi'an Jiaotong University and immunized intraperitoneally at 2-week intervals with the purified CDV-F protein $(100 \mu \mathrm{g} /$ mouse $)$ for a total of three inoculations. For the first immunization, the protein was emulsified with an equal volume of Freund's complete adjuvant. For the other two inoculations, protein was emulsified with Freund's incomplete adjuvant. One month after the third injection, the titers of antibodies against CDV-F protein in 
serum samples from the mice were detected by indirect ELISA using the purified recombinant protein CDV-F protein as coating antigen. Before harvesting cells for cell fusions to generate hybridomas, mice were given a final booster injection by tail vein. Five days later, mice were anesthetized with a dose of ketamine and acepromazine $(100 \mathrm{mg} / \mathrm{kg} \mathrm{K}+5 \mathrm{mg} / \mathrm{kg}$ A) via intraperitoneal injection then sacrificed by cervical dislocation. Next, spleen cells from immunized mice were fused with SP2/0 murine myeloma cells using a standard polyethylene glycol-mediated fusion method. Hybridoma cell lines secreting antibodies against CDV-F protein were identified using indirect ELISA then positive hybridoma lines were subcloned twice to establish stable clones. Next, mAbs in culture supernatants were purified using Protein G columns according to the manufacturer's instructions (Jinsite Company, Nanjing, China). Purified mAbs were analyzed by SDS-PAGE, and their concentrations were calculated from spectrophotometrically determined absorbance values based on an absorption coefficient of $\mathrm{OD}_{280 \mathrm{~nm}} /(1.35 \mathrm{mg} / \mathrm{mL})$. Animal experiments were conducted under the guidelines of Animal Care and Use Committee of Northwest Agricultural \& Forestry University (NWSUAF, Permit Number: AE189693).

To determine which mAbs bound specifically with the $F$ protein of CDV particles, the purified mAbs were used as primary antibodies for conducting $\mathrm{F}$ protein detection in CDV-inoculated Vero cells via immunofluorescence assays (IFAs) (Yahara et al. 2002).

To identify mAbs isotypes, the Mouse Monoclonal Antibody Isotyping Reagents (ISO2) (Sigma) kit was used according to the manufacturer's instructions.

To determine the spatial relationships of epitopes recognized by the mAbs in this study (Dong et al. 2011; Zhou and Afshar 1999), the purified mAbs were first conjugated to horseradish peroxidase (HRP) using a peroxidase-labeling kit according to the manufacturer's instructions (Roche Diagnostics, Basel, Switzerland). Next, the HRP-labeled antibody was used in a competitive ELISA that was performed according to the procedure described below.

\section{Indirect and competitive ELISAs}

Indirect ELISA was used to detect the titers of anti-CDV-F protein antibodies in immunized mouse sera and identify the mAbs against CDV-F protein in hybridoma supernatants binding with the antigens in 96-well plates (Nunc). Plates were coated with purified CDV-F protein (200 ng/well) and incubated at $4{ }^{\circ} \mathrm{C}$ overnight then blocked with blocking buffer (PBS-T: $0.01 \mathrm{M}$ PBS, pH 7.2, supplemented with $2.5 \%$ dried milk $(w / v)$ and $0.5 \%$ Tween-20 $(v / v))$ at room temperature (RT) for $1 \mathrm{~h}$. Sera (diluted in blocking buffer) or hybridoma supernatants were added and incubated at RT for $1 \mathrm{~h}$. Antimouse IgG $(\mathrm{H}+\mathrm{L})$-HRP (Jackson ImmunoResearch, USA) was then added and incubated at RT for $1 \mathrm{~h}$ followed by addition of tetramethylbenzidine (TMB) (A: $205 \mathrm{mM}$ potassium citrate ( $\mathrm{pH} 4.0)$; B: $41 \mathrm{mM}$ tetramethylbenzidine; A:B $(v / v)=39: 1)$ to induce the colorimetric reaction. Finally, the $\mathrm{OD}_{450 \mathrm{~nm}}$ values were read using an automated ELISA plate reader (Bio-Rad, USA) after the reaction was stopped by the addition of $3 \mathrm{M} \mathrm{H}_{2} \mathrm{SO}_{4}$.

Competitive ELISA was used to determine the spatial relationships of epitopes recognized by the mAbs developed in this study. First, the titers of HRP-conjugated mAbs (HRP$\mathrm{mAbs}$ ) at dilutions of $10^{-1}$ to $10^{-4}$ were measured using direct ELISA. Dilutions of HRP-mAbs used in competitive ELISAs were selected based on $\mathrm{OD}_{450 \mathrm{~nm}}$ values of approximately 1 as determined previously by direct ELISA. Using purified CDV$F$ protein as coating antigen for the competitive ELISA, the mAbs were used as competitors then HRP-mAbs were sequentially added into wells. After color development of reactions proceeded, reactions were stopped and $\mathrm{OD}_{450 \mathrm{~nm}}$ values were recorded. Maximal binding without inhibition was found when HRP-mAbs were added without competitors. The percentage of inhibition was calculated using the formula: $100 \times\left[1-\left(\mathrm{OD}_{450} \mathrm{~nm}\right.\right.$ of HRP-mAbs and $\left.\mathrm{mAb}\right) /\left(\mathrm{OD}_{450 \mathrm{~nm}}\right.$ of HRP-mAb)]. Competitive binding of a given HRP-mAb was considered inhibited if binding was decreased by $40 \%$ or more.

\section{Development of double monoclonal antibody-based sandwich ELISA}

To develop the sandwich ELISA, the pair of mAbs was selected as capture and detection reagents. An orthogonal experiment using these mAbs was designed as follows: first, the different mAbs ( $800 \mathrm{ng} /$ well) were used to coat wells of ELISA plates as capture antibodies and incubated at $4{ }^{\circ} \mathrm{C}$ overnight. After plates were blocked and washed, CDV viral stock (positive control, P) or culture supernatant of normal Vero cells (negative control, N) were added. After washing again, equivalent amounts of individual HRP-mAbs were added to separate wells. After a final wash, TMB was added to induce the colorimetric reaction and $\mathrm{OD}_{450 \mathrm{~nm}}$ values were read after reactions were stopped. Selection of the best pair of $\mathrm{mAbs}$ was based on the highest $\mathrm{P} / \mathrm{N}$ value.

Second, optimal amounts of capture mAb and detection HRP-mAb for the sandwich ELISA were determined using a checkerboard titration method (Chen et al. 2016; Liu et al. 2014). Different amounts of capture mAb (100, 200, 400, 800 , and $1000 \mathrm{ng} /$ well) and different dilutions of HRP-mAb $(1: 1,1: 10,1: 100,1: 1000$, and $1: 10,000)$ were used in the sandwich ELISA. The CDV viral stock $(100 \mu \mathrm{L} /$ well $)$ served as positive control and the same volume of normal Vero cell culture supernatant served as negative control. Optimal amounts of capture mAb and detection HRP-mAb were determined based on the highest $\mathrm{P} / \mathrm{N}$ value. 


\section{Validation of the sandwich ELISA}

To determine the cutoff value for positive results of the sandwich ELISA developed here, the 120 negative samples, including cloacal swabs $(n=25)$ from pet dogs, supernatants from normal Vero cell cultures $(n=15)$ and serum and fecal samples from healthy pet dogs $(n=80)$ were tested. Clinical samples were collected and used for evaluating the sandwich ELISA with the consent of the animal owners. Cloacal swabs and fecal samples were suspended in 100-200 $\mu \mathrm{L}$ PBS, then ground and centrifuged. The cutoff value for interpretation of positive and negative results was based on the mean $\mathrm{OD}_{450 \mathrm{~nm}}$ value obtained from values of 120 negative samples plus 3 standard deviations (SD) to ensure the cutoff value would provide $99 \%$ confidence for discriminating between positive and negative results.

To determine the viral detection limit of the sandwich ELISA developed here, different amounts (from $10 \mathrm{TCID}_{50}$ to $10^{4} \mathrm{TCID}_{50}$ ) of $\mathrm{CDV}$ viral stocks were tested using the sandwich ELISA and compared to results obtained for known amounts of virus tested using commercial immune colloidal gold test strips (Beijing Anheal Laboratories Company, Beijing, China).

To determine the specificity of the sandwich ELISA, other canine disease viruses, including canine parvovirus (CPV), canine infectious hepatitis virus (ICHV), and canine parainfluenza virus (CPIV), were also tested using the assay.

The reproducibility of the sandwich ELISA was evaluated by testing 3 positive (CDV viral stock) and 3 negative samples (supernatants from normal Vero cell cultures). The coefficient of variation (CV) was used to evaluate the inter-assay variation (between plates) and the intra-assay variation (within a plate). The six samples were tested using three different plates tested on different occasions to determine the inter-assay $\mathrm{CV}$, while three replicates within each plate were used to calculate the intra-assay $\mathrm{CV}$.

\section{Comparison between sandwich ELISA and commercial immune colloidal gold test strips}

To determine the agreement rate of CDV detection results obtained for clinical samples using the sandwich ELISA developed here and commercial immune colloidal gold test strips, 43 serum samples (13 panda and 30 dog specimens) and 56 clinical fecal samples from dogs were tested using both methods. The result of the agreement rate between the two test methods was calculated using EXCEL software based on test results for each specimen.

\section{Statistical analysis}

Kappa index values were calculated to estimate the level of coincidence of results obtained via sandwich ELISA versus commercial immune colloidal gold test strips. These calculations were performed using SPSS software (version 20).

\section{Results}

\section{Production of recombinant CDV-F protein}

To produce mAbs against CDV-F protein, the recombinant CDV-F protein was expressed in an E. coli system to yield inclusion bodies. The SDS-PAGE analysis of inclusion body proteins indicated the presence of CDV-F protein with a molecular weight of approximately $40 \mathrm{kDa}$, as expected (Fig. 1a). Next, the F protein was purified using a Ni-NTA resin column; then, the SDS-PAGE analysis was conducted and demonstrated the presence of highly pure recombinant $\mathrm{F}$ protein (Fig. 1a). This protein was subsequently shown via Western blot analysis to possess antigenic epitopes that bound to antiCDV antibody from dogs possessing strong immunity to CDV (Fig. 1b). Therefore, the purified CDV-F protein was suitable for use as an immunizing antigen to generate mAbs in $\mathrm{BALB} / \mathrm{c}$ mice.

\section{Production and characterization of $\mathrm{mAbs}$ against CDV-F protein}

Four BABL/c mice were immunized with purified recombinant CDV-F protein. After three immunizations, the antibody titers of serum samples collected from four immunized mice were all $1: 10^{5}$, suggesting that an immune response to recombinant CDV-F protein had been induced in each mouse (Fig. 2a). Next, cells from one randomly selected immunized mouse were used to generate mAbs via methods based on traditional hybridoma technology.

Three mAbs designated 1A5, 1A6, and 7D5 were successfully produced that subsequently were shown to possess $\operatorname{IgG} 2$, IgG2, and IgG1 isotypes, respectively. After concentration followed by purification over a goat anti-mouse IgG affinity column, the mAbs 1A5, 1A6, and 7D5 were successfully purified (Fig. 2b) and had concentrations of $1.31 \mathrm{mg} / \mathrm{mL}$, $1.05 \mathrm{mg} / \mathrm{mL}$, and $1.25 \mathrm{mg} / \mathrm{L}$, respectively. Indirect ELISA and Western blot analysis results showed that these three mAbs specifically reacted with recombinant CDV-F protein and not with recombinant CDV $\mathrm{N}$ protein expressed using the same vector and bacterial system (Fig. 2c and d). In addition, IFA results showed that each of the three mAbs could bind to F protein present in CDV-infected Vero cells, suggesting all three $\mathrm{mAbs}$ recognized the $\mathrm{F}$ protein of CDV particles (Fig. 3).

After the three mAbs were labeled with HRP, the titers of HRP-1A5, HRP-1A6, and HRP-7D5 were determined to be $10^{-2}, 10^{-3}$, and $10^{-4}$, respectively, via direct ELISA (Fig. 4). Next, the competitive ELISA results showed that addition of 


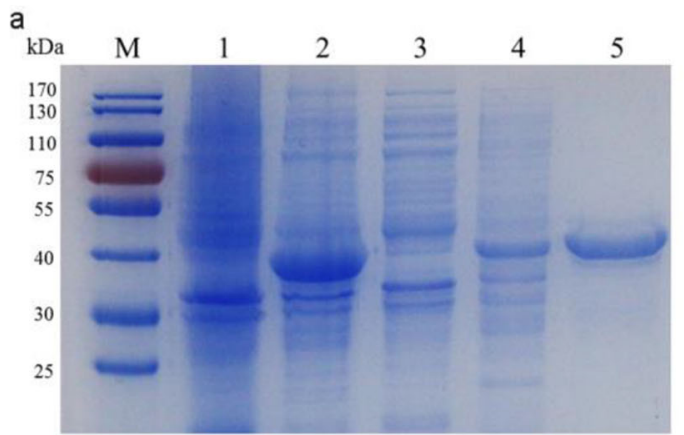

b

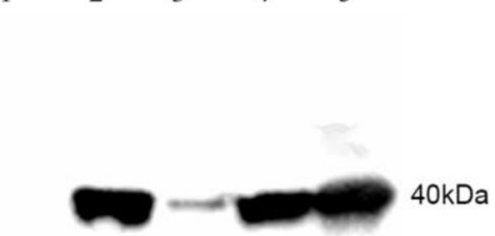

Fig. 1 Expression, purification, and identification of recombinant CDVF protein with the bacterial system. a SDS-PAGE analysis. M: protein marker; lane 1: pET-28a vector control; lane 2: bacterial lysates of the CDV-F; lane 3: solution protein; lane 4: inclusion body; lane 5: purified

protein. The relative molecular masses of CDV-F protein was about $40 \mathrm{kDa}$. b Antigenic analysis of Western blot, lanes 1-5: same as a, reaction with high immune antibody against CDV from the dog
IA5 inhibited HRP-1A5 binding to CDV-F protein by $86.21 \%$, while binding was not inhibited by $1 \mathrm{~A} 6$ and 7D5, as evidenced by low percent inhibition (PI) values of $8.03 \%$ and $10.15 \%$, respectively (Table 1 ). And binding of HRP-1A6 to $\mathrm{CDV}-\mathrm{F}$ protein was inhibited by unlabeled $1 \mathrm{~A} 6$, as evidenced by the resulting PI value of $90.12 \%$, but not by $1 \mathrm{~A} 5$ and 7D5, as evidenced by low respective PI values of $7.32 \%$ and $12.09 \%$ (Table 1). These results indicate that the three mAbs, 1A5, 1A6, and 7D5, recognize different epitopes within the CDV-F protein.
Fig. 2 Screening, purification, and characterization the mAbs against the CDV-F protein. a Titers of antibodies against CDV$\mathrm{F}$ protein in the sera from the BABL/c mice after the third immunization. b SDS-PAGE analysis of purified mAbs $1 \mathrm{~A} 5,1 \mathrm{~A} 6$, and 7D5. Specific reactions between the 3 screened mAbs and CDV-F protein using indirect $\mathbf{c}$ ELISA and $\mathbf{d}$ Western blot. $\mathbf{d} \mathrm{M}$ : protein marker; lanes 1,3 , and 5 : purified mAbs 1A5, 1A6, and 7D5 reacted with CDV-F protein, respectively; lanes 2, 4, and 6 : purified mAbs 1A5, 1A6, and 7D5 not reacted with CDV-N protein, respectively
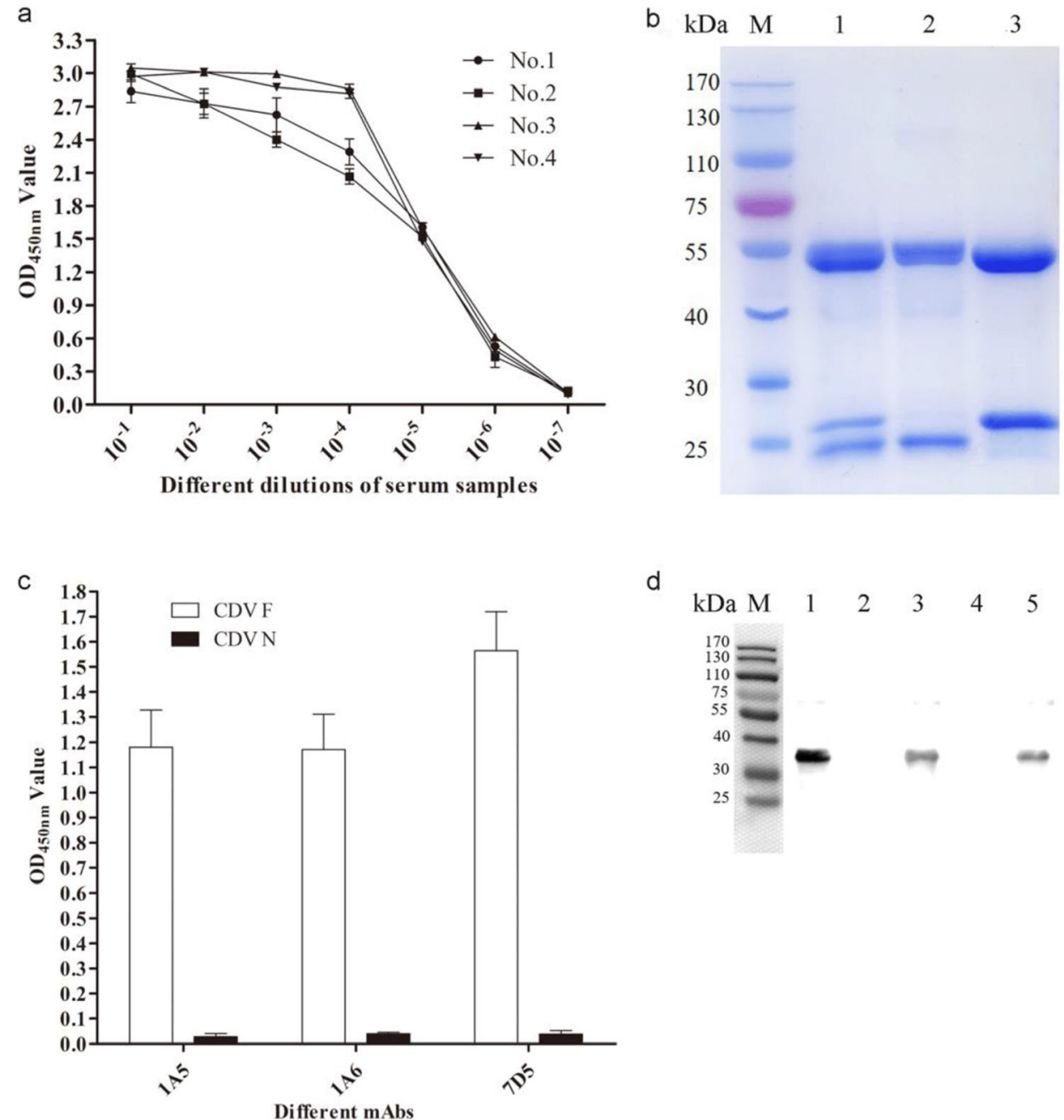

d

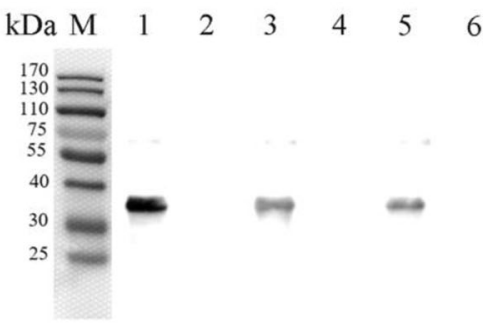



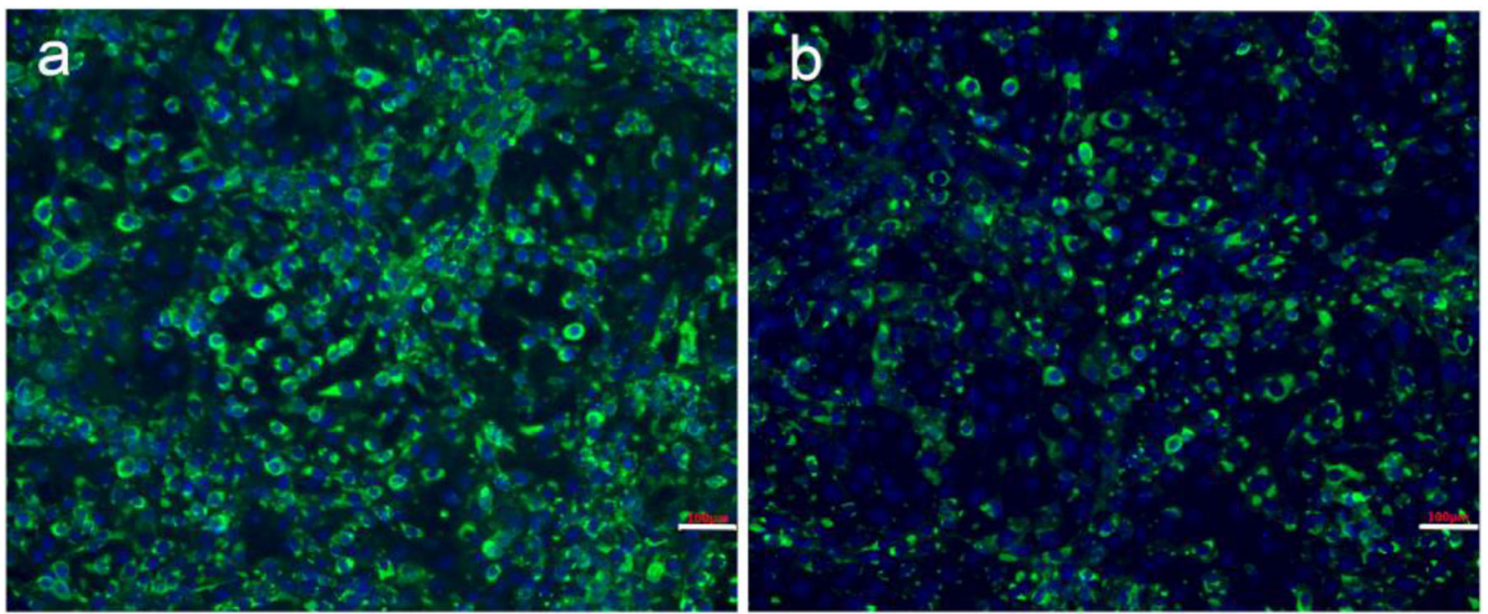

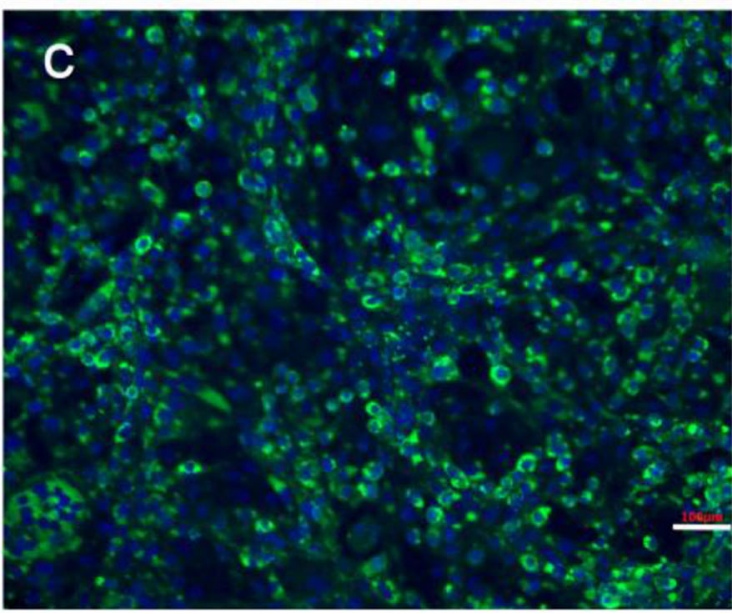

Fig. 3 Immunofluorescence assay of three mAbs binding with CDV-F protein in the CDV-infected Vero cells. The CDV-F protein was detected using $\mathrm{mAbs}$ and FITC-conjugated goat anti-mouse IgG. a $1 \mathrm{~A} 5$ binding

\section{Development of the monoclonal antibody-based sandwich ELISA}

To select the best pair of mAbs for use in the sandwich ELISA, the mAbs 1A5, 1A6, and 7D5 were tested separately as capture antibodies and HRP-1A5, HRP-1A6, and HRP7D5 were tested separately as detection antibodies. Results showed that the $\mathrm{P} / \mathrm{N}$ value (10.736) was highest for $\mathrm{mAb}$ pair $1 \mathrm{~A} 6$ and HRP-7D5 (Table 2).

To optimize amounts of mAb 1A6 and 7D5-HRP for the ELISA, a checkerboard titration assay was used to demonstrate that the optimal amount of mAb $1 \mathrm{~A} 6$ protein was $800 \mathrm{ng} / \mathrm{well}$ and the optimal dilution of 7D5-HRP was 1:10² $(500 \mu \mathrm{g} / \mathrm{mL})$, as shown by the highest $\mathrm{P} / \mathrm{N}$ value (11.45) obtained using these conditions (Table 3 ).

After conditions were optimized, the sandwich ELISA was performed as follows: first, the 96-well plate was coated with $800 \mathrm{ng} /$ well of mAb $1 \mathrm{~A} 6$ in PBS buffer and incubated at $4{ }^{\circ} \mathrm{C}$ overnight (Table 3). The next day, plate wells were blocked with blocking buffer ( $300 \mu \mathrm{L} /$ well) for $1 \mathrm{~h}$ at RT then washed

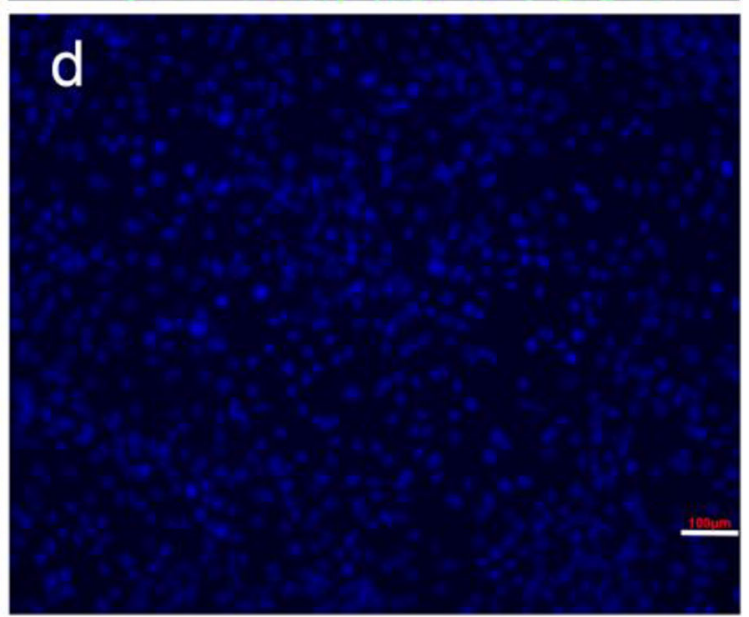

with CDV-F protein. b $1 \mathrm{~A} 6$ binding with CDV-F protein. $\mathbf{c} 7 \mathrm{D} 5$ binding with CDV-F protein. d Negative control using the mouse IgG as the primary antibody

three times with the PBS-T ( $300 \mu \mathrm{L} /$ well). Next, test samples $(100 \mu \mathrm{L})$ were added to wells and plates were incubated for $1 \mathrm{~h}$ at RT. After three washes, HRP-7D5 (diluted 1:100 to $500 \mu \mathrm{g} / \mathrm{mL}, 100 \mu \mathrm{L} /$ well) was added then plates were incubated for $1 \mathrm{~h}$ at RT (Table 3). After a final wash, TMB $(100 \mu \mathrm{L} /$ well $)$ was added to induce the colorimetric reaction and $\mathrm{OD}_{450 \mathrm{~nm}}$ values were read using an automated ELISA plate reader after the reaction was stopped with $3 \mathrm{M} \mathrm{H}_{2} \mathrm{SO}_{4}$ (50 $\mu \mathrm{L} /$ well).

\section{Cutoff value of the developed sandwich ELISA}

Using the abovementioned procedures, the 120 negative samples were tested using the sandwich ELISA, yielding an average $\mathrm{OD}_{450 \mathrm{~nm}}$ value of 0.121 with $\mathrm{SD}$ of 0.025 . The cutoff value of the sandwich ELISA was calculated to be 0.196 $(0.121 \pm 3 \mathrm{SD})$. Therefore, CDV detection results obtained via sandwich ELISA with $\mathrm{OD}_{450 \mathrm{~nm}}$ values $\geq 0.196$ were scored positive for CDV. 
Fig. 4 Analysis of the titers of three HRP-labeled mAbs (HRP1A5, HRP-1A6, and HRP-7D5) to detect CDV-F using direct ELISA. The three HRP-mAbs in a dilution range of $10^{0}$ to $10^{-5}$ were tested for reaction with the CDV-F protein in the direct ELISA

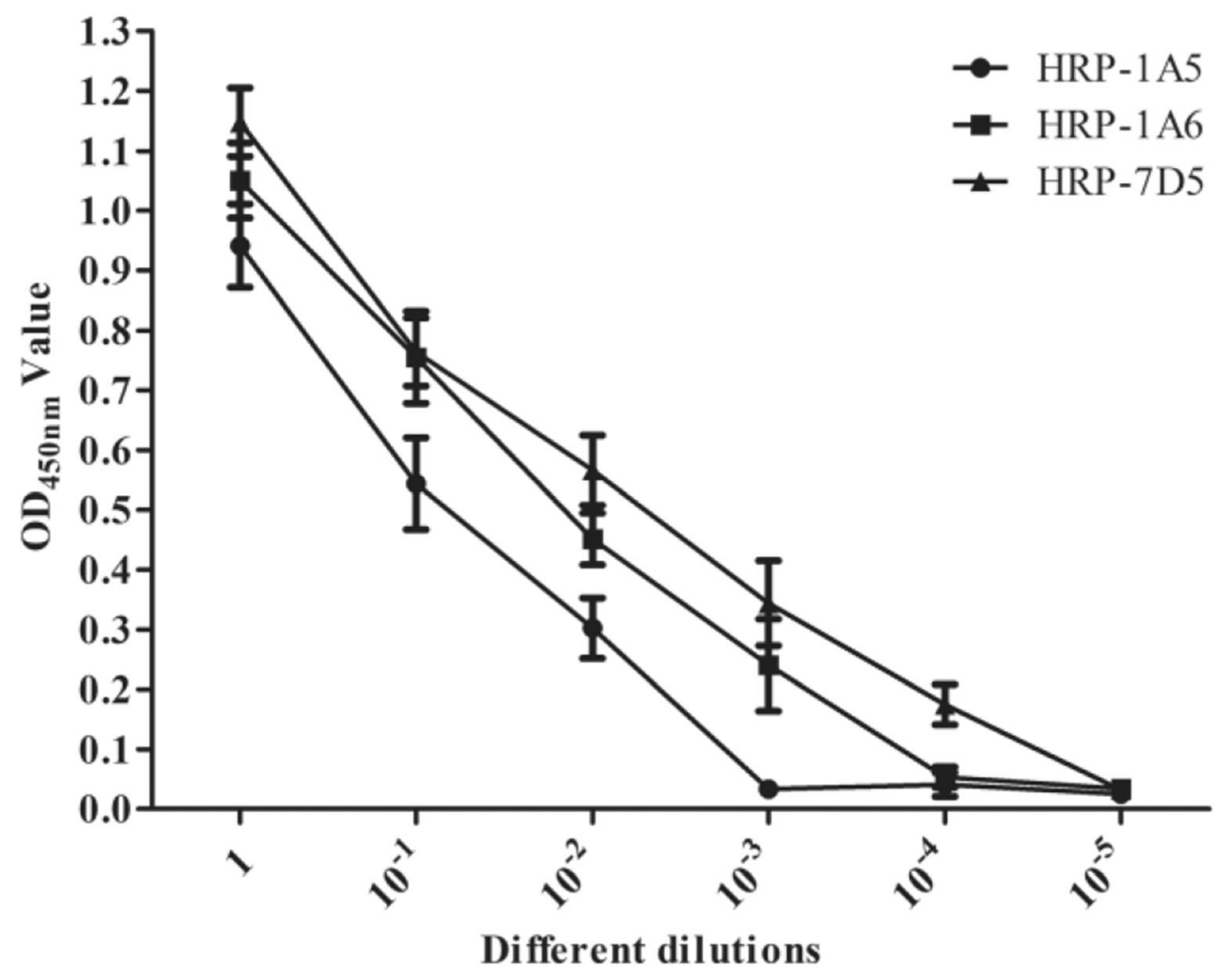

\section{Limitations, specificity, and reproducibility of the sandwich ELISA}

For determining the lowest detection limit of the sandwich ELISA, different amounts of CDV viral stock were tested using the assay. The results showed that for amounts of CDV stock above $100 \mathrm{TCID}_{50}$ per $100 \mu \mathrm{L}$, the $\mathrm{OD}_{450 \mathrm{~nm}}$ values of the sandwich ELISA were all greater than 0.196, indicating that the minimum amount of CDV detected by the assay was $100 \mathrm{TCID}_{50}$ per $100 \mu \mathrm{L}$ (Fig. 5). Meanwhile, test results obtained for various amounts of CDV using the commercial immune colloidal gold test strip reflected a similar low limit of detection as that obtained using sandwich ELISA (Fig. 5).

To determine the specificity or sandwich ELISA crossreactivity toward other canine disease viruses, three viruses (CPV, ICHV, and CPIV) were tested via the CDV sandwich

Table 1 Binding inhabitation of the three labeled mAbs to the recombinant CDV-F protein

\begin{tabular}{llll}
\hline HRP-labeled mAbs & \multicolumn{3}{l}{ Percent } \\
\cline { 2 - 4 } & $1 \mathrm{~A} 5$ & $1 \mathrm{~A} 6$ & $7 \mathrm{D} 5$ \\
\hline HRP-1A5 & 86.21 & 8.03 & 10.15 \\
HRP-1A6 & 7.32 & 90.12 & 12.09 \\
HRP-7D5 & 9.12 & 8.41 & 84.37 \\
\hline
\end{tabular}

ELISA, yielding $\mathrm{OD}_{450 \mathrm{~nm}}$ values of $0.034-0.118$, as compared to CDV detection values of $0.46-1.23$ for similar quantities of virus. Thus, these results demonstrate that the sandwich ELISA is specific for CDV detection.

By testing three positive and three negative samples in triplicate, intra-assay $\mathrm{CV}$ values for the $\mathrm{OD}_{450 \mathrm{~nm}}$ values were

Table 2 Optimization of the best pair of antibodies for developing the sandwich ELISA

\begin{tabular}{lllll}
\hline Capture antibody & Sample & \multicolumn{2}{l}{ Detection antibody } \\
\cline { 3 - 5 } & & HRP- & HRP- & HRP- \\
& & 1A5 & 1A6 & 7D5 \\
\hline 1A5 & P & - & 0.876 & 0.756 \\
& N & - & 0.123 & 0.088 \\
& P/N & - & 7.121 & 8.617 \\
1A6 & P & 0.801 & - & 1.121 \\
& N & 0.130 & - & 0.104 \\
& P/N & 6.162 & - & 10.736 \\
$7 D 5$ & P & 0.901 & 0.765 & - \\
& N & 0.129 & 0.119 & - \\
& P/N & 6.969 & 6.407 & - \\
\hline
\end{tabular}

Mabs 1A5,1A6 and 7D5 were used as the capture antibody and 1A5HRP, 1A6-HRP and 7D5-HRP as the detection antibody. CDV viral stock was as the positive control $(\mathrm{P})$ and culture supernatant of normal Vero cells as the negative control $(\mathrm{N})$. Italic represents the best conditions 
Table 3 Optimization of the amount of capture mAb $1 \mathrm{~A} 6$ and dilution of detection antibody HRP-7D5 for developing the sandwich ELISA

\begin{tabular}{llllll}
\hline \multirow{2}{*}{ Different amounts of 1A6 (ng/well) } & Samples & \multicolumn{4}{l}{ Different dilutions of HRP-7D5 } \\
\cline { 3 - 6 } & & $1: 10$ & $1: 10^{2}$ & $1: 10^{3}$ & $1: 10^{4}$ \\
\hline 200 & $\mathrm{P}$ & 0.801 & 0.825 & 0.432 & 0.214 \\
& $\mathrm{~N}$ & 0.128 & 0.094 & 0.068 & 0.075 \\
& $\mathrm{P} / \mathrm{N}$ & 6.253 & 8.776 & 6.326 & 2.834 \\
400 & $\mathrm{P}$ & 0.867 & 0.901 & 0.567 & 0.354 \\
& $\mathrm{~N}$ & 0.122 & 0.091 & 0.075 & 0.104 \\
& $\mathrm{P} / \mathrm{N}$ & 7.123 & 9.876 & 7.523 & 3.738 \\
& $\mathrm{P}$ & 1.023 & 1.123 & 0.735 & 0.358 \\
& $\mathrm{~N}$ & 0.139 & 0.098 & 0.100 & 0.088 \\
& $\mathrm{P} / \mathrm{N}$ & 7.345 & 11.45 & 7.362 & 4.043 \\
& $\mathrm{P}$ & 1.121 & 0.987 & 0.632 & 0.441 \\
& $\mathrm{~N}$ & 0.144 & 0.105 & 0.104 & 0.098 \\
& $\mathrm{P} / \mathrm{N}$ & 7.762 & 9.362 & 6.102 & 4.501 \\
\hline
\end{tabular}

CDV viral stock was as the positive control $(\mathrm{P})$ and culture supernatant of normal Vero cells the negative control (N). Italic represents the best conditions observed to range from 3.56 to $8.37 \%$, with a median value of $6.13 \%$. When the six samples were tested in triplicate in three different plates at different times, the inter-assay $\mathrm{CV}$ of $\mathrm{OD}_{450 \mathrm{~nm}}$ values ranged from 4.53 to $9.13 \%$, with a median value of $7.37 \%$. These data indicate that the monoclonal antibody-based sandwich ELISA developed here for CDV detection exhibits good reproducibility.

\section{Agreement between the sandwich ELISA and commercial immune colloidal gold test strip assay}

A total of 43 serum samples (from 13 pandas and 30 dogs) and 56 clinical dog fecal samples were tested for CDV via both the sandwich ELISA and commercial immune colloidal gold test strips. Subsequently, sandwich ELISA results exhibited 100\% agreement with commercial immune colloidal gold test strip results for CDV detection in serum samples and $96.4 \%$ for CDV detection in clinical dog fecal samples (Table 4). Moreover, statistical analysis showed a high level of agreement between results obtained using sandwich ELISA and commercial immune colloidal gold test strip (kappa coefficient $=0.742)$.

\section{Discussion}

CDV infection is a highly contagious disease that affects domestic dogs, wild animals, endangered species and some important economic animals. Rapid and sensitive laboratory and field tests for CDV infection diagnosis are essential in disease control. Sandwich ELISA methods based on monoclonal antibody have been shown to have many advantages, such as
Fig. 5 Determination of the limitation of the developed monoclonal antibody-based sandwich ELISA to detect CDV. The different amounts of CDV stock $\left(\mathrm{TCID}_{50}\right)$ were detected by both the developed sandwich ELISA and commercial immune colloidal gold test strip

\section{Commercial immune colloidal gold test strip}

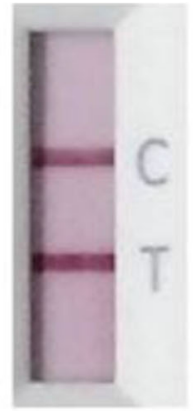

4

1.032

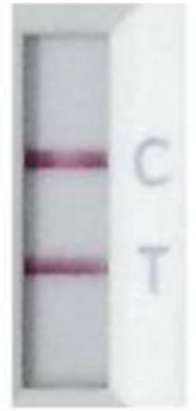

3

0.786

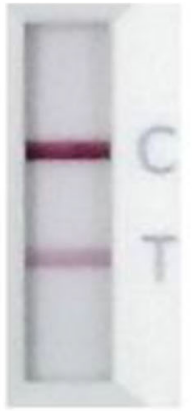

2

0.463

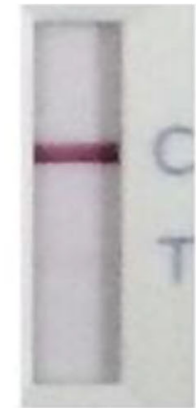

1

$$
\mathrm{OD}_{450 \mathrm{~nm}} \text { value }
$$

(Sandwich ELISA) 
Table 4 Comparisons of the developed sandwich ELISA with the commercial immune colloidal gold test trip by detecting serum and fecal samples

\begin{tabular}{|c|c|c|c|c|c|c|c|}
\hline \multirow[t]{2}{*}{ Samples } & \multirow[t]{2}{*}{ Species } & \multirow[t]{2}{*}{ Number } & \multirow[t]{2}{*}{ Sandwich ELISA } & \multicolumn{2}{|c|}{ Commercial immune colloidal gold test } & \multirow[t]{2}{*}{ Agreement (\%) } & \multirow[t]{2}{*}{ Kappa valu } \\
\hline & & & & + & & & \\
\hline \multirow[t]{3}{*}{ Sera } & Giant panda & 13 & & 0 & 13 & \multirow[t]{3}{*}{100} & \multirow[t]{3}{*}{0.742} \\
\hline & \multirow[t]{2}{*}{ Dog } & 6 & \multirow[t]{2}{*}{+} & 6 & 0 & & \\
\hline & & 24 & & 0 & 24 & & \\
\hline \multirow[t]{2}{*}{ Feces } & \multirow[t]{2}{*}{ Dog } & 24 & + & 22 & 2 & \multirow[t]{2}{*}{96.4} & \\
\hline & & 32 & & 0 & 32 & & \\
\hline
\end{tabular}

good specificity, high sensitivity, easy standardization, easy mass production, and suitable for high-throughput testing of clinical samples. For these reasons, sandwich ELISA have been applied to the detection of various viruses (Luo et al. 2020; Shao et al. 2019). At present, CDV detection has been limited to the diagnosis of clinical symptoms, serological detection, electron microscopy, and molecular biological test methods. Out of which, the virus isolation and immunohistochemistry detection methods are technically complex and cumbersome. RT-PCR and real-time PCR are widely used for CDV detection, due to their exceptional sensitivity and accuracy (Brown et al. 2020; Jin et al. 2017; Li et al. 2018a, b). However, the two assays were also cumbersome and needed to extract the viral RNA from the samples. Meanwhile, for the RT-PCR and real-time PCR, the professional lab was needed to prevent nucleic acid contamination. In addition, the immune colloidal gold test strip has also been widely used because of its convenience. But the high cost of it, which cost about 2.7-4.4 USD per sample, is already becoming a major burden for the detection of a large number of samples. In contrast, the ELISA is more economical in field testing. Here, the developed sandwich ELISA in the study only cost approximately 0.29 USD per sample, which is much lower than the immune colloidal gold test strip.

CDV-F protein is the viral structural protein that constitutes viral surface protuberances (Wang et al. 2019). Notably, CDV-F protein epitopes have been shown to be the most highly conserved epitopes among different CDV isolates. Therefore, the CDV-F protein was used in this study as the target antigen for preparation of monoclonal antibodies for the sandwich ELISA developed here. Subsequently, all three mAbs obtained in this work were of the IgG subtype, which facilitated further purification. These antibodies were found to be highly specific for CDV-F and thus did not bind appreciably to other CDV proteins. In addition, the three $\mathrm{mAbs}$ recognized different $\mathrm{F}$ protein epitopes and their spatial conformations were unaffected by HRP labeling, as shown by competitive ELISA. Thus, these results collectively suggest that the CDV-F protein-based sandwich ELISA developed here may be used to detect diverse CDV isolates (Plattet et al. 2007; Wang et al. 2019); in the future, we plan to test numerous CDV isolates to assess whether this assay has universal applicability for detection of diverse CDV isolates.

In this study, mAbs were produced and paired for use in a robust sandwich ELISA for detecting CDV in clinical samples. This detection method provides good specificity for CDV with no observed cross-reactions with other pathogenic canine viruses. Due to the high specificities of mAbs developed here for CDV, the limit of detection of the ELISA approached $100 \mathrm{TCID}_{50} / \mathrm{mL}$ of CDV, the same limit of detection obtained using commercial immune colloidal gold test strips. Analysis of results between the sandwich ELISA and commercial immune colloidal gold test strips for CDV infection from serum and fecal samples revealed high agreement (kappa coefficient $=0.742$ ) for efficient detection of CDV antigen in clinical samples, highlighting the feasibility of the sandwich ELISA developed here for clinical use.

CDV infection is a growing concern for farmers breeding important economic animals in China, due to steadily increasing numbers of vulnerable farmed mink, ferret, and racoon dogs. Importantly, a canine distemper-like disease has been observed in vaccinated farmed minks, foxes, and raccoon dogs in Shandong, Liaoning, Hebei, and Heilongjiang provinces in northeastern China (Tao et al. 2020). The double monoclonal antibody-based sandwich ELISA established here is easy to conduct and adaptable for high-throughput applications for surveillance of CDV outbreaks in farmed minks, ferrets, and racoon dogs. In the future, testing of numerous clinical samples from such farms will require high-throughput assays to monitor viral infections in the field.

In conclusion, three mAbs specific for CDV-F protein, 1A5, 1A6, and 7D5, were generated in this work using traditional hybridoma cell technology. All three mAbs could bind to the F protein of native CDV particles and thus were suitable for use in a double monoclonal antibody-based sandwich ELISA to detect CDV. Subsequently, mAbs 1A6 and 7D5 were shown to be most suitable for this purpose due to their 
high sensitivity and high specificity and reproducibility for CDV antigen detection. Therefore, we believe that the sandwich ELISA developed in this work will likely be ideal for surveillance efforts to detect CDV infections in the field.

Acknowledgments We thank Xinze Qu from Soinvet Biotechnology Corporation for kindly providing the CDV strain Onderstepoort and other canine virus antigens.

Authors' contributions Y.Z., G.X., Q.Z., Y.S., and E-M.Z. designed the study; Y.Z., G.X., L.Z., J.K.Z., and P.J. performed the experiments; G.X., B.L., Y.L., J.F.Z., Y.S., and E-M.Z. analyze the experimental data; Y.Z., Q.Z., Y.S., and E-M.Z. wrote and revised the manuscript. All the authors reviewed the manuscript and approved the final version.

Funding The research is funded by grants from Key Projects of State Forestry Administration of China (2016-02) and National Key R\&D Program of China (2017YFD0501000 and 2016YFD0500706).

\section{Compliance with ethical standards}

Conflict of interest The authors declare that they have no conflicts of interest.

Ethical approval This article does not contain any studies with human participants performed by any of the authors. All animal studies with BALB/c mouse were approved by Animal Care and Use Committee of Northwest Agricultural \& Forestry University (NWSUAF, Permit Number: AE189693).

Open Access This article is licensed under a Creative Commons Attribution 4.0 International License, which permits use, sharing, adaptation, distribution and reproduction in any medium or format, as long as you give appropriate credit to the original author(s) and the source, provide a link to the Creative Commons licence, and indicate if changes were made. The images or other third party material in this article are included in the article's Creative Commons licence, unless indicated otherwise in a credit line to the material. If material is not included in the article's Creative Commons licence and your intended use is not permitted by statutory regulation or exceeds the permitted use, you will need to obtain permission directly from the copyright holder. To view a copy of this licence, visit http://creativecommons.org/licenses/by/4.0/.

\section{References}

Barben G, Stettler M, Jaggy A, Vandevelde M, Zurbriggen A (1999) Detection of IgM antibodies against a recombinant nucleocapsid protein of canine distemper virus in dog sera using a dot-blot assay. Zentralbl Veterinarmed A 46(2):115-121

Beineke A, Baumgärtner W, Wohlsein P (2015) Cross-species transmission of canine distemper virus-an update. One Health 1:49-59

Brown AT, McAloose D, Calle PP, Auer A, Posautz A, Slavinski S, Brennan R, Chris Walzer C, Seimon TA (2020) Development and validation of a portable, point-of-care canine distemper virus qPCR test. PLoS One 15(4):0232044-0232065

Chen Y, Zhao Q, Liu B, Wang L, Sun Y, Li H, Wang X, Syed SF, Zhang G, Zhou EM (2016) A novel blocking ELISA for detection of antibodies against hepatitis E virus in domestic pigs. PLoS One 11(3): 0152639-0152653
Cho KH, Kim J, Yoo HA, Dae-hee K, Seung-yong P, Chang-seon S, Insoo C, Joong-bok L (2014) Use of hydrophilic extra-viral domain of canine distemper virus $\mathrm{H}$ protein for enzyme-linked immunosorbent assay development. J Vet Sci 15(4):503-509

David K, Neeta S, Nadine AE, Michael H, Pascal M, Richard KP, KarlHeinz A, Johannes PL, Flavio G, Lindenmann U, Rainer R, Fotiadis D, Plattet P (2019) Primary resistance mechanism of the canine distemper virus fusion protein against a small-molecule membrane fusion inhibitor. Virus Res 259:28-37

Deem SL, Spelman LH, Yates RA, Montali RJ (2000) Canine distemper in terrestrial carnivores: a review. J Zoo Wildl Med 31(4):441-451

Dong S, Zhao Q, Lu M, Sun P, Qiu H, Zhang L, Lv J, Zhou EM (2011) Analysis of epitopes in the capsid protein of avian hepatitis $\mathrm{E}$ virus by using monoclonal antibodies. J Virol Methods 171(2):374-380

Duque-Valencia J, Sarute N, Olarte-Castillo XA, Ruíz-Sáenz J (2019) Evolution and interspecies transmission of canine distemper virusan outlook of the diverse evolutionary landscapes of a multi-host virus. Viruses 11(7):582-604

Elia G, Decaro N, Martella V, Cirone F, Lucente MS, Lorusso E, Di Trani L, Buonavoglia C (2006) Detection of canine distemper virus in dogs by real-time RT-PCR. J Virol Methods 136(1-2):171-176

Jin Y, Zhang X, Ma Y, Qiao Y, Liu X, Zhao K, Zhang C, Lin D, Fu X, Xu X, Wang Y, Wang H (2017) Canine distemper viral infection threatens the giant panda population in China. Oncotarget 8(69): 113910-113919

Kim D, Jeoung SY, Ahn SJ, Lee JH, Pak S, Kwon HM (2006) Comparison of tissue and fluid samples for the early detection of canine distemper virus in experimentally infected dogs. J Vet Med Sci 68(8):877-879

Li C, Guo D, Wu R, Kong F, Zhai J, Yuan D, Sun D (2018a) Molecular surveillance of canine distemper virus in diarrhoetic puppies in Northeast China from May 2014 to April 2015. J Vet Med Sci 80(6):1029-1033

Li S, Yi L, Cao Z, Cheng YN, Tong MW, Wang JK, Lin P, Cheng SP (2018b) Identification of linear B-cell epitopes on the phosphoprotein of canine distemper virus using four monoclonal antibodies. Virus Res 257:52-56

Liu B, Zhao Q, Sun Y, Wang X, Zhao J, Du T, Wang C, Xiao S, Mu Y, Zhang G, Luo J, Hsu WH, Zhou EM (2014) Development of a blocking ELISA for detection of antibodies against avian hepatitis E virus. J Virol Methods 204:1-5

Loots AK, Mitchell E, Dalton DL, Kotzé A, Venter EH (2017) Advances in canine distemper virus pathogenesis research: a wildlife perspective. J Gen Virol 98(3):311-321

Luo SS, Deng XW, Xie ZX, Huang JL, Zhang MX, Li M, Xie LJ, Li D, Fan Q, Wang S, Zeng TT, Zhang YF, Xie ZQ (2020) Production and identification of monoclonal antibodies and development of a sandwich ELISA for detection of the H3-subtype avian influenza virus antigen. AMB Express 10(1):49-57

Martella V, Elia G, Lucente MS, Decaro N, Lorusso E, Banyai K, Blixenkrone-Møller M, Lan NT, Yamaguchi R, Cirone F, Carmichael LE, Buonavoglia C (2007) Genotyping canine distemper virus (CDV) by a hemi-nested multiplex PCR provides a rapid approach for investigation of CDV outbreaks. Vet Microbiol 122(12):32-42

Martinez-Gutierrez M, Ruiz-Saenz J (2016) Diversity of susceptible hosts in canine distemper virus infection: a systematic review and data synthesis. BMC Vet Res 12:78-88

Nemeth NM, Oesterle PT, Campbell GD, Ojkic D, Jardine CM (2018) Comparison of reverse-transcription real-time PCR and immunohistochemistry for the detection of canine distemper virus infection in raccoons in Ontario, Canada. J Vet Diagn Investig 30(2):319-323

Plattet P, Cherpillod P, Wiener D, Zipperle L, Vandevelde M, Wittek R, Zurbriggen A (2007) Signal peptide and helical bundle domains of virulent canine distemper virus fusion protein restrict fusogenicity. J Virol 81(20):11413-11425 
Pope JP, Miller DL, Riley MC, Anis E, Wilkes RP (2016) Characterization of a novel canine distemper virus causing disease in wildlife. J Vet Diagn Investig 28(5):506-513

Rendon-Marin S, da Fontoura Budaszewski R, Canal CW, Ruiz-Saenz J (2019) Tropism and molecular pathogenesis of canine distemper virus. Virol J 16(1):30-44

Shao HS, Wang P, Wang WK, Zhang JJ, Li TF, Liang GC, Gao W, Qin AJ, Ye JQ (2019) A novel monoclonal antibodies-based sandwich ELISA for detection of serotype 4 fowl adenovirus. Avian Pathol 48(3):204-208

Sidhu MS, Husar W, Cook SD, Dowling PC, Udem SA (1993) Canine distemper terminal and intergenic non-protein coding nucleotide sequences: completion of the entire CDV genome sequence. Virology 193(1):66-72

Soma T, Ishii H, Hara M, Ohe K, Hagimori I, Ishikawa Y, Taneno A (2003) Detection of canine distemper virus antigen in canine serum and its application to diagnosis. Vet Rec 153(16):499-501

Tao R, Ba H, Chen J, Liu M, Pan H, Li X, Wang Q, Zhao J (2020) Phylodynamic analysis of two amino acid substitutions in the hemagglutinin protein of canine distemper virus strains detected in furbearing animals in China. Virus Genes 56(1):58-66

von Messling V, Springfeld C, Devaux P, Cattaneo R (2003) A ferret model of canine distemper virus virulence and immunosuppression. J Virol 77(23):12579-12591
Wang JC, Wang JF, Li RW, Liu LB, Yuan WZ (2017) Rapid and sensitive detection of canine distemper virus by real-time reverse transcription recombinase polymerase amplification. BMC Vet Res 13(1):241-247

Wang J, Luo Y, Liang L, Li J, Cui S (2018) A fast and simple one-step duplex PCR assay for canine distemper virus (CDV) and canine coronavirus (CCoV) detection. Arch Virol 163(12):3345-3349

Wang W, Feng W, Li D, Liu S, Gao Y, Zhao Z, Fu Q, Yan L, Zheng W, Li M, Zheng X (2019) Fusion and hemagglutinin proteins of canine distemper virus promote osteoclast formation through NF- $\mathrm{kB}$ dependent and independent mechanisms. Exp Cell Res 378(2):171181

Yahara Y, Ohkubo Y, Kariwa H, Takashima I (2002) Evaluation of enzyme-linked immunosorbent assay (ELISA) and immunofluorescent antibody (IFA) test for the detection of Porcine Reproductive and Respiratory Syndrome Virus (PRRSV) antibody in pigs from conventional farms. J Vet Med Sci 64(7):583-588

Zhou E, Afshar A (1999) Characterisation of monoclonal antibodies to epizootic hemorrhagic disease virus of deer (EHDV) and bluetongue virus by immunisation of mice with EHDV recombinant VP7 antigen. Res Vet Sci 66(3):247-252

Publisher's note Springer Nature remains neutral with regard to jurisdictional claims in published maps and institutional affiliations. 